A Trade-Level DEA Model to Evaluate Relative Performance of Investment Fund Managers

Rajiv Banker, Janice Y.S. Chen, Paul Klumpes

PII:

S0377-2217(16)30393-9

DOI:

10.1016/j.ejor.2016.05.056

Reference:

EOR 13742

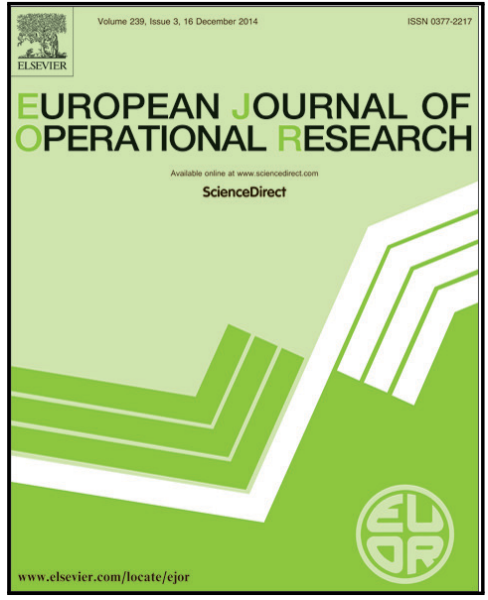

To appear in:

European Journal of Operational Research

Received date:

28 August 2013

Revised date:

31 March 2016

Accepted date:

25 May 2016

Please cite this article as: Rajiv Banker, Janice Y.S. Chen, Paul Klumpes, A Trade-Level DEA Model to Evaluate Relative Performance of Investment Fund Managers, European Journal of Operational Research (2016), doi: 10.1016/j.ejor.2016.05.056

This is a PDF file of an unedited manuscript that has been accepted for publication. As a service to our customers we are providing this early version of the manuscript. The manuscript will undergo copyediting, typesetting, and review of the resulting proof before it is published in its final form. Please note that during the production process errors may be discovered which could affect the content, and all legal disclaimers that apply to the journal pertain. 


\section{Highlights}

- We develop a trade-level measure to evaluate fund managers' trading efficiency.

- We build an additive DEA model to focus on adjusted returns during different periods.

- We find that fund managers have asymmetric ability in buying and selling.

- $\quad$ Trading diversity and portfolio have similar effects on both buy and sell efficiency. 


\section{A Trade-Level DEA Model to Evaluate Relative Performance of Investment Fund Managers}

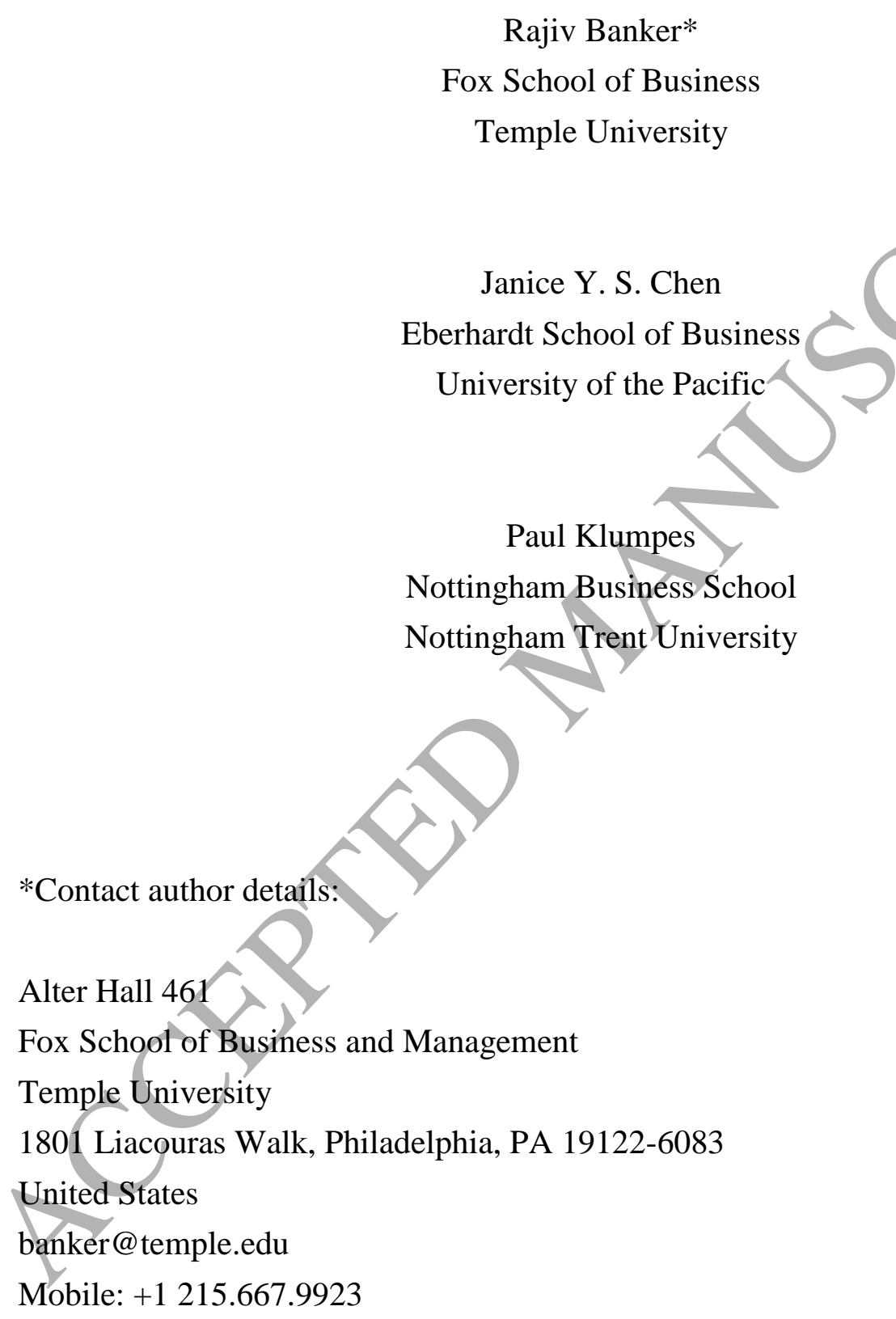

This Version: December 26, 2015 


\title{
A Trade-Level DEA Model to Evaluate Relative Performance of Investment Fund Managers
}

\begin{abstract}
We develop a trade-level measure to evaluate fund managers' efficiency in their buying and selling activities relative to the trades of other fund managers $\wedge \mathrm{We}$ customize an additive Data Envelopment Analysis (DEA) model to focus on risk-adjusted returns during different time periods as trade-level outcomes. The model does not consider any input-output process. Instead, it considers tradeoffs between multiple outcomes. We find that fund managers do not have symmetric ability in buying and selling. Some managers do well in buy transactions but not in sell transactions while others perform well in selling but not in buying. We also explore the determinants of fund managers' trading performance. Compared to trade characteristics, portfolio characteristics have a greater influence in explaining fund managers' relative trading efficiency.
\end{abstract}

Keywords: fund manager performance; data envelopment analysis; trade characteristics; portfolio characteristics 


\section{Introduction}

Evaluation of managerial performance is always a challenge even when reliable market based information is available for the consequences of managerial actions. In this study, we report on the broad insights obtained from our work with a mutual fund company that sought to evaluate the buying and selling ability of its fund managers relative to each other. We customize an additive Data Envelopment Analysis (DEA) model to provide the research client an alternative method to rank fund managers' performance and examine how trade and portfolio characteristics explain differences in the trading efficiency of fund managers. We find that fund managers do not have symmetric ability in their buy and sell transactions, and portfolio characteristics have a greater influence than trade characteristics in explaining fund managers' relative efficiency. While traditional portfolio performance measures focus on performance relative to a capital market model, our analysis emphasizes evaluation of fund manager performance measured as risk-adjusted returns at the trade level and assessed relative to the trades of other fund managers with the company.

The literature on mutual fund performance measurement can be traced to the beginning of asset pricing theory. Jensen (1968) and Treynor (1965) provided some of the earliest formal measures based on the capital asset pricing model (CAPM). Recent studies of mutual fund returns based on arbitrage pricing theory (APT) have moved beyond CAPM-based performance measures (e.g. Carhart, 1997, Daniel et al, 1997). These studies account for different risk factors in the crosssection of expected returns, such as size, book-to-market value and momentum. In practice, the Sharpe Ratio is a popular industry standard because it is directly computable from an observed series of returns without any additional information (Sharpe, 1994). However, it is based on restrictive properties of estimated alpha in 
reflecting the overall performance outcome of a portfolio. None of the above models explicitly exploit more detailed information available at the decision-level. The performance of managers of actively managed funds depends largely on their efficiency in timing their buy and sell trades. Wermers (2000) documents that the average turnover ratio for some actively managed funds is over $150 \%$, indicating that the holding period of each stock in their portfolios, on average, is less than 8 months. Our contribution in this study is in adapting the generic additive DEA model to fit the context of evaluating fund managers' performance based on detailed return data for each trade.

In this paper we propose an alternative fund performance measure based on the notion of relative efficiency. Our customized DEA model provides relative performance information at the transaction level. We posit that for active fund managers, it is important to focus on their disaggregated performance for each trade and explore the granular drivers of their trading performance. For this purpose, we develop our model to evaluate the relative efficiency of each of their trades. Thus, in our model, each trade is a decision making unit (DMU) and its risk-adjusted returns for different time periods are the outcomes.

Unlike conventional performance measurement methods, DEA is a non-parametric method which does not impose theoretical assumptions of any model from financial theory (such as CAPM or APT) to construct a benchmark. Instead, our DEA model measures how well each trade of a fund manager performs relative to the best trades of all managers in the reference group. This relative performance measure provides our research client relevant information to select, train and reward fund managers and organize their portfolios. Additionally, DEA is flexible and can evaluate performance on a number of different timing dimensions simultaneously. In contrast, the prior literature on fund performance often focuses the frame of 
reference for evaluation to only one horizon (usually one year) at a time in the analysis (e.g. Carhart, 1997). Accordingly, our measure is more useful for those actively managed funds whose turnover rate is high, and the holding period is low. Our model has the flexibility to place a greater performance weight on returns in shorter term horizons or in a manner that reflects different strategic considerations. Moreover, our second stage regression analysis identifies the transaction-level drivers of fund managers' trading efficiency that can help our research client improve fund managers' future trading performance. Our DEA model can supplement traditional portfolio performance measures by extracting information from/trades that can improve internal management of fund portfolios.

DEA has long been used to measure the performance of financial investments. Murthi et al. (1997) evaluate the efficiency of 2,083 mutual funds over one year. Basso and Funari (2001) measure the efficiency of 47 mutual funds between 1997 and 1999. Other applications of DEA to measure mutual fund performance include Morey and Morey (1999), Basso and Funari (2003), Lozano and Gutierrez (2008) and Lamb and Tee (2012). Some recent papers also apply DEA to evaluate hedge fund performance (e.g. Gregoriou, 2003; Gregoriou et al, 2005; Eling, 2006, Kumar et al, 2010). They pay more attention to different downside risk measures in order to capture the tail risk in hedge fund returns. In contrast, we focus on mutual fund managers' relative performance measured at the buy and sell transactions level.

Unlike the standard BCC model (e.g. Banker, Charnes, and Cooper, 1984) we do not consider a production process relating inputs to outputs. Instead, we leverage the ability of the $\mathrm{BCC}$ model to compare performance of an observation with convex combinations of other observed performance. In our model, the DMU corresponds to each trade conducted by each fund manager. The performance 
outcomes for each trade (=DMU) are measured as post-buy (positive orientation) or post-sell (negative orientation) risk-adjusted returns in three consecutive time horizons.

We consider the outcomes of each trade relative to others. We do not model or estimate a production process relating some inputs to some outputs (Banker, Chang, Janakiraman and Konstans, 2004). We build an additive DEA model for our study rather than the standard radial model because our observations are returns for each trade, not traditional inputs and outputs in a production function, and many of them have negative values. Instead, we model overall efficiency)as the weighted sum of the efficiency for each of the three outcomes separately, where the weight on each outcome corresponds to its strategic importance. We measure the efficiency for each outcome as the slack in the constraint corresponding to that outcome. Thus, the efficiency for each outcome is measured as the additive difference between the actual outcome and the corresponding outcome of a virtual reference unit constructed as a convex combination of observed outcomes of other trades.

Our model measures each fund manager's performance separately for each trade at the buy and sell transaction level. We aggregate the relative efficiencies of all buy or all sell trades of a fund manager to measure his overall buy or sell efficiency. Based on this first stage efficiency analysis, we can further examine in a second stage regression analysis whether fund managers have equal ability in both buying and selling, or how trade and portfolio characteristics explain fund managers' buy or sell trading efficiency (Banker and Natarajan, 2008).

In the second stage, we regress fund managers' relative efficiency on possible determinants of their relative trading efficiency. We find that portfolio characteristics have considerable influence on fund managers' relative trading efficiency. The major overall finding of our second stage analysis is that fund 
managers have asymmetric performance in buy trades and sell trades. Some managers do well in buy transactions but not in sell transactions while others perform well in sell but not in buy transactions. An important implication of this result for fund managers' performance evaluation is that we should consider portfolio characteristics (such as portfolio diversification and portfolio size) and recognize fund managers' asymmetric ability in buy and sell trades when evaluating their performance.

The remainder of this paper is organized as follows We first describe our unique dataset in section 2 and then introduce the additive DEA model we employ to evaluate fund managers' relative trading efficiency in section 3 . We report our empirical results and main findings with robustness checks in section 4 . Finally, we conclude in section 5 with a discussion of our results and directions for future research.

\section{Data Description}

The dataset in this study is at the granular trading level, which allows us to closely observe fund managers' trading decisions in buying and selling respectively and precisely measure their performance. Unlike other mutual fund databases, our dataset is at the transaction level. There are 23,408 transactions in our dataset provided by a mutual fund management consulting firm. These trades are conducted by 18 fund managers. In addition to North America, these fund managers also trade securities in Europe, Asia and Oceania, depending on their specialization. Our transactional dataset therefore includes global securities.

For each transaction, we have its cumulative returns in the periods prior to and subsequent to the trade date. Our research client adjusts returns for risk considerations employing a proprietary multi-factor model. We have returns for six 
different periods: 12 to 6 months (Pre12-6), 6 to 3 months (Pre6-3) and 0-3 months (Pre3-0) prior to the trade date and 0-3 months (Post0-3), 3 to 6 months (Post3-6) and 6 to 12 months (Post6-12) subsequent to the trade date. Figure 1 depicts the six time periods for the returns in each trade.

The primary objective of our study is to develop a trade-level performance measure based on the concept of relative efficiency to satisfy the research client's need for granular, benchmarked performance measures. Our relative performance measure considers each trade's timing of returns in different periods. In addition, we have separate datasets for buy and sell transactions which allow us to examine fund managers' buying and selling activities separately. Most other related studies conduct their analyses only at the fund portfolio level and they cannot directly measure fund managers' buy and sell performance. For example, the mutual fund database, Thomson/CDA, covers the mutual fund portfolio holdings on a quarterly basis. As a result, previous studies using this database estimate fund trades by tracking changes in holdings from quarter to quarter. With our unique database, we can directly capture fund managers' performance in trading for each of their transactions. Therefore we can more precisely measure the buy and sell performance of each fund manager. In addition to cumulative returns for each transaction, our dataset includes portfolio specific data, such as the company name, trading date, market value and trading price for each transaction.

We first filter out transactions with insufficient information, such as missing returns or missing identification as either buy trades or sell trades. Table 1 reports summary characteristics of the 23,408 transactions that we use in our analysis (11,496 relate to buying activities and 11,912 relate to selling activities). Table 1 also shows the mean, median, and standard deviation of the cumulative return prior to the trade date and after the trade date for each transaction. The transactions are 
performed by 18 fund managers over a two-year period. The sample period is not characterized by unusually high levels of volatility or extremes of economic activity.

\section{Estimation Models}

We use DEA-based nonparametric estimation procedures to estimate efficiency scores evaluating fund managers' performance in each of their buy and sell trades relative to all trades of all 18 fund managers. These scores differ from traditional, portfolio level performance measures that are often used by investment fund managers, such as those based on the capital asset pricing model and the arbitrage pricing theory model. DEA modeling in general does not impose the assumptions of any financial model to construct a benchmark. Instead, DEA models

construct a benchmark relative to the actual performance of other fund managers. Buy low and sell high is obviously the best investment strategy to generate profits. Analyzing post-buy returns is the most simple and direct way to evaluate fund managers' buy performance. Analogously, the timing of a sell transaction is more profitable if post-sell returns are lower.

We modify the Banker, Charnes, and Cooper (BCC) (1984) model into an additive model to compare these buy transactions' post-trade returns in three different periods. The standard BCC model is not appropriate in our study because our observations are returns and many of them have negative values. Negative values in the standard BCC model confound the correct ranking of transactions' relative efficiency because the relative inefficiency of each observation is defined as a ratio of the weighted sum of returns for all observations over the reference set. To address this problematic issue, we modify the standard BCC model to an additive model so that the relative inefficiency measure $\theta$ captures the shortfall in returns 
relative to the reference set. It is not affected by negative values and reflects the correct ranking of each observation.

For each transaction in our buy sample, we have its 0 to 3 month (Post0-3), 3 to 6 month (Post3-6) and 6 to 12 month (Post6-12) post-buy returns. The 3 returns for each of the three time periods are the transaction's three outcomes $\left(\mathrm{y}_{1}, \mathrm{y}_{2}\right.$ and $\left.\mathrm{y}_{3}\right)$. Our DEA model for the buy transactions is similar to the standard DEA model with three outputs and no input except for the additive efficiency structure. We define the efficiency score to be $\eta_{j}{ }^{*}=\exp \left(-\theta_{j}^{*}\right)$ where $\theta_{j}{ }^{*}$ is as specified below in Model (1):

$$
\theta_{j}^{*}=\operatorname{Max} \sum_{t=1}^{T} r_{t} \theta_{t}
$$

subject to

$$
\sum_{k=1}^{K} \lambda_{k}=1
$$

$$
\sum_{k=1}^{K} \lambda_{k} y_{t k}-\theta_{t j} \geq y_{t j} \text { for } t=1, \ldots T
$$

$$
\lambda_{k}, \theta_{t j} \geq 0
$$

where $\mathrm{j}$ and $\mathrm{k}$ represent each of 11,496 buy transactions, $\mathrm{t}$ denotes the three periods after the trade (so that $\mathrm{T}=3$ in our example), and $\lambda_{\mathrm{k}}$ is the weight on each reference transaction $\mathrm{k}$. Thus, for our study, we have returns for three different periods $(\mathrm{t}=1$, 2, 3) corresponding to the three outcomes (returns during Post0-3, Post3-6 and "Post6-12). Since there are 11,496 transactions in our buy sample, "k" ranges from 1 to 11,496 . The weights $r_{t}$ can be different for each period depending on the strategic importance of returns in each time period based on a variety of managerial considerations. For example, to evaluate fund managers who trade actively, we can call attention to their performance in short term horizons immediately after their trading by putting more weight on the inefficiency score in the post $0-3$ or 3-6 month 
period. To disguise the research client's strategic considerations, we cannot disclose the exact values of the weights $r_{t}$ used in our analysis. We present our empirical results using their actual weights chosen such that $r_{1}>r_{2}>r_{3}$ to reflect the relatively higher importance of short term returns in the relative efficiency analysis. We also repeated the analysis with all three weights set to be equal; the results reported in our subsequent regression analysis are robust to this alternative set of weights.

For each transaction $\mathrm{j}$, our objective function is to maximize the weighted sum of the post-buy returns from all three periods. This optimization process constructs an efficient frontier so that we can evaluate the performance of transaction $\mathrm{j}$ relative to all transactions $\mathrm{k}$, including itself. In our buy model, we have three positively oriented performance measures (0-3 month $\left(\mathrm{y}_{1}\right), 3-6$ month $\left(\mathrm{y}_{2}\right)$, and 6-12 month $\left(\mathrm{y}_{3}\right)$ post-buy returns) and there is no input. Here $\theta_{\mathrm{j}}{ }^{*}$ is the weighted sum of the slacks in constrains for the three time periods for each transaction $j$. The smaller the $\theta_{\mathrm{j}}{ }^{*}$, the greater are the post-buy returns of this trade $\mathrm{j}$ and the higher is the transaction efficiency. Since $\theta_{\mathrm{j}}^{*} \in[0, \infty), \eta_{\mathrm{j}}{ }^{*}=\exp \left(-\theta_{\mathrm{j}}{ }^{*}\right)$ ranges between 0 and 1 consistent with the common expectation for efficiency. Using linear programming to solve this problem, we obtain 11,496 estimates of $\theta_{\mathrm{j}}^{*}$ corresponding to each of the 11,496 trades. The greater the efficiency score, the better has the fund manager performed in that trade. In the following sections, we use the trade-level efficiency score $\eta_{\mathrm{j}}^{*}$ to perform our analysis.

We apply this method in a similar fashion to evaluate fund managers' performance in their sell transactions. In fund management, selling stocks at a high before the prices decline creates value. Therefore, we use the negative of post-sell returns in each time period to measure each sell transaction's efficiency. The post-sell returns could also be viewed as the opportunity cost of not holding the stock any longer after it is sold. Accordingly, more negative or less positive post-sell 
returns mean that greater value was created and lower opportunity costs were incurred. We take the negative of post-sell returns for 0 to 3 month (Post $0-3), 3$ to 6 month (Post3-6) and 6 to 12 month (Post6-12) to measure each transaction's negatively oriented outcomes. Using these three stock returns denoted here by $\mathrm{x}_{1}, \mathrm{x}_{2}$ and $\mathrm{x}_{3}$, we measure the efficiency of each of the 11,912 sell transactions relative to other sell transactions. We define the sell efficiency score $\omega_{j}{ }^{*}$ for each transaction $\mathrm{j}$ as $\omega_{\mathrm{j}}{ }^{*}=$ $\exp \left(-\phi_{\mathrm{j}}{ }^{*}\right)$ where the following Model (2) gives us each sell transaction's inefficiency measure:

$\phi_{j}^{*}=\operatorname{Max} \sum_{t=1}^{T} r_{t} \phi_{t j}$

subject to

$\sum_{k=1}^{K} \lambda_{k}=1$

$\sum_{k=1}^{K} \lambda_{k} x_{t}+\phi_{t j} \leq x_{t j}$ for $t=1, \ldots T$ $\lambda_{k}, \phi_{t j} \geq 0$

where $\mathrm{j}$ and $\mathrm{k}$ represent transactions, $\mathrm{t}$ denotes the three periods, $\lambda_{\mathrm{k}}$ is the weight on each reference transaction $\mathrm{k}$. We have returns for three different periods treated as inputs (Post0-3, Post3-6 and Post6-12), "t" is from 1 to 3 . Since there are 11,912 transactions in our sell sample, "k" ranges from 1 to $11,912$.

\section{Empirical Results}

\section{Baseline efficiency scores}

Table 2 shows the distribution of our DEA efficiency scores in buy and sell transactions respectively. We construct two different market value weighted DEA efficiency scores for each fund manager, -- one for buy transactions and another 
for sell transactions - that provide aggregated efficiency scores for each fund manager based on his/her detailed transactions. The fund manager with the highest value weighted DEA efficiency is ranked as first and so on. From Table 3 it appears that fund managers have asymmetric performance in buying and selling. For example, fund manager $\mathrm{R}$ is ranked at the top in buying but at the bottom in selling. Fund manager P performs well in buying but not in selling. Fund manager $\mathrm{G}$ is ranked in the top three in selling but in the bottom two in buying.

In general, about half of the 18 fund managers have asymmetric performance in buying and selling. Figure 2 displays the degree of asymmetry in fund managers' ability in buying and selling. The X-axis of this plot is a fund manager's buy rank while the Y-axis is the fund manager's sell rank. The 18 dots represent the 18 fund managers' performance in buy trades and sell trades. If fund managers have the same ability in buying and selling, the dots should lie on the 45 degree line. However, we cannot find any pattern from the dots and the rank correlation between buy rank and sell rank is insignificant.

Our transaction based efficiency measure also provides insights on the determinants of fund managers' managerial performance. If a mutual fund company relies only on traditional portfolio performance measures which do not distinguish buy performance from sell performance, it is likely that they may draw inaccurate inferences. To further analyze the drivers of fund managers' trading performance, in the following section we employ second stage regression analysis to explore how fund managers' portfolio and trading characteristics influence their trading performance (Banker and Natarajan, 2008).

\section{Portfolio and Trading Characteristics Analysis}

Prior research has examined the impact of mutual funds' portfolio characteristics and of fund investment style on fund performance. Portfolio 
characteristics such as fund size, portfolio diversification, and fee structure influence fund performance (e.g. Dahlquist, 2000; Haslem et al, 2008). The investment styles refer to the stock (or trading) characteristics chosen by the fund, such as market capitalization, book-to-market equity value, and prior-period return (momentum). Even though both portfolio characteristics and trading characteristics are highly related to fund performance, they have different implications for fund managers' performance. Portfolio characteristics (such as portfolio size) act as the endowment of the fund manager that cannot be changed easily or controlled fully by fund managers. By contrast, trading characteristics are decided by the fund manager and reveal more information about fund manager's ability in trading. In this regression analysis we examine whether fund managers' trading efficiency is correlated with their portfolio characteristics or trading characteristics.

Limited by information available in our dataset, we examine two portfolio characteristics (trading diversification and portfolio size) and two trading characteristics (trading frequency and stock's past performance). The first characteristic we investigate is trading diversification. We construct a measure similar to Herfindahl index, which is defined as the sum of squares of the market value of stocks traded by the fund manager divided by the market value of his/her trading portfolio:

$$
H H I_{i}=\sum_{n=1}^{N}\left(\frac{S V_{n i}}{T V_{i}}\right)^{2}
$$

where $\mathrm{SV}_{\mathrm{ni}}$ is the market value of stock $\mathrm{n}$ traded (bought or sold) by fund manager $\mathrm{i}$, and TV is the total market value of fund manager i's trading portfolio. Therefore each fund manager has two HHI indexes, a buy HHI and a sell HHI. A high HHI implies low trading diversification. 
We analyze the influence of trading diversification for buy and sell transactions separately in order to determine whether fund manager's trading diversification influences his/her trading efficiency. As documented in previous finance literature, a diversified portfolio reduces the variance of the portfolio and thus diversification is one technique to reduce investment risk. If a fund manager holds a less diversified portfolio, it implies that his/her portfolio has a higher probability of generating extreme positive or negative returns. If a fund manager diversifies his/her trading portfolio and follows more different stocks then, it is also more likely that he/she identifies more investment opportunities and obtains good trades. Hence, we hypothesize that diversification has a positive impact on a fund manager's efficiency score.

The second portfolio level characteristic that prior literature documents as impacting fund manager's performance is the relative size of his/her trading portfolio. In microeconomics, economies of scale refer to the increase in efficiency of production as the quantity of the goods being produced increases. The increase in efficiency in that context is due to the decrease in average costs per unit. Whether there exist economies of scale in the active money management industry is still an open question in finance (Elton et al, 2012). Thus, if economies of scale prevail, the size of fund managers' trading portfolio will be positively correlated with trading efficiency. Since our efficiency measure is the relative score, we use the relative size of the fund manager's trading portfolio (measured as the market value of a fund manager's portfolio divided by the total market value of all fund managers' portfolios) as the scale measure, instead of using the absolute value of the portfolio size.

Various trading characteristics or fund manager attributes may also influence a manager's observed trading efficiency (Hu et al, 2012). An important factor is trading frequency, which is the number of times a stock is bought or sold by 
the fund manager. Frequent trading incurs greater transaction costs. If a fund manager is involved in active trading, this indicates that he/she is acting on good information, and the trading profits can cover the transaction costs. Wermers (2000) documents that active funds can beat the Vanguard Index 500 fund. He shows that active fund managers have greater stock-picking ability to cover the transaction costs that are incurred. Therefore, we also hypothesize that active trading is positively related to our relative trading efficiency measure. Each fund manager has two measures for trading frequency, one for the buy sample and the other for the sell sample. Both measures are likely to be related positively to trading frequency.

We also consider the influence of past/performance measuring the momentum factor documented in the finance literature. Jegadeesh and Titman (1993) find that abnormal returns can be obtained by buying winners and selling losers. Carhart (1997) includes this momentum factor as a common factor to explain fund performance and documents a positive relationship. On the other hand, De Bondt and Thaler $(1985,1987)$ argue that stock prices overreact to information and suggest that contrarian strategies, buying losers and selling winners, can generate abnormal returns. The two investment strategies, momentum and contrarian, are commonly used by institutional investors. Since the fund managers in our sample may use either or both momentum and contrarian strategies, we do not assume that a specific strategy is optimal. Therefore, we examine whether trading efficiency is affected by the stock's past performance without predicting the direction.

The regression model we use to estimate the relation between trading efficiency and the various portfolio and trading characteristics outlined above is specified as follows:

$$
\text { Efficiency }_{j}=\alpha_{0}+\beta_{1} * H H I_{i}+\beta_{2} * \text { Size }_{i i}+\gamma_{1} * \text { TFreq }_{j}+\gamma_{2} *\left(\operatorname{Re} t_{-} 3 M\right)_{j}+\varepsilon_{j}
$$


We perform the regression analysis separately for our buy and sell samples. Our dependent variable is the relative efficiency score of each transaction $\mathrm{j}$ and our independent variables are each manager i's trading diversification index (HHIi), the relative size of each manager i's trading portfolio, trading frequency of stock $\mathrm{j}$ (the number of times stock $\mathrm{j}$ is traded by the fund manager) and 3-month pre-trade returns. We also add the 12-month pre-trade return as a robustness check.

Table 4 presents results from the regression model for the portfolio and trading characteristics analysis. We find that $\mathrm{HHI}$ is negatively related to the relative efficiency for both buy and sell transactions. In other words, the greater the diversification of the trading, the higher the relative efficiency is. In finance theory, given the same expected return, a diversified portfolio creates better performance by reducing return variance. Pollet and Wilson (2008) document that diversification improves fund performance. Higher trading diversification with higher efficiency score suggests that to some extent our efficiency measure can capture information of both return and risk. Since our efficiency measures are positively related to trading diversification, this implies that fund managers can further improve their performance by their skill in identifying good trades instead of investing in certain high risk stocks and gambling for higher returns.

Relative size is positively and significantly related to both buy and sell efficiency. The higher trading efficiency of larger trading portfolios supports our hypothesis that fund managers' trading portfolios exhibit economies of scale. We also compare the size of our fund managers' trading portfolio with the size of mutual funds from the CRSP database. The size of our fund managers' trading portfolio varies widely from $10^{\text {th }}$ to $90^{\text {th }}$ percentile of the distribution of the size of the mutual funds from the CRSP database. 
Trading frequency is positively and significantly associated with relative efficiency in both buy and sell samples. This result supports our hypothesis that active fund managers act on good information. Our results are also consistent with Wermer's (2000) finding that active fund management is a valuable skill. As for the momentum factor (measured as the past 3-month return) the coefficients are negative but insignificant in both buy and sell samples. This result implies that a stock's past performance does not have a significant impact on fund managers' relative trading efficiency on average. Regression results are similar when we include fund managers' 12 month pre-trade returns instead.

We report some untabulated standard régression diagnostics at the insistence of one of the four referees. We caution readers to be extremely careful in attaching any meaning to these statistics because the second stage analysis in DEA is not just another simple regression model (Banker and Natarajan, 2008) and properties of these diagnostic statistics have not been explored or derived as yet. We present three common robustness tests for ordinary regression results. For multicollinearity diagnosis, we follow Belsey, Kuh, and Welsch (1980) approach. According to their tests, none of the explanatory variables cause dependencies that affect the regression estimates. We also perform rank regression with our data to check monotonic but non-linear relationships. All the portfolio and trading characteristics have the same direction of significant effects on the trading efficiency measures as reported in our tables. Furthermore, our regression results also hold after we drop influential observations. All these untabulated results may suggest that the second stage regression results are robust to diagnostic checks.

In Table 4, the coefficients in buy and sell efficiency regressions have the same sign and are similar in their corresponding magnitudes. We test whether the coefficients are equal between the buy sample and the sell sample. The p-values for 
these tests are shown in the last column of Table 4 (Diff_Buy-Sell). Since the p-values are all greater than 0.10 , the coefficients in buy and sell efficiency regressions are not significantly different. This result suggests that portfolio and trading characteristics have similar impacts on buy and sell trading efficiency. Since buy and sell trading efficiency scores are not significantly correlated, it appears that individual factors other than portfolio and trading characteristics influence the asymmetry.

Finally, we investigate whether trading efficiency is influenced more by portfolio characteristics (HHI and relative size) or by trading characteristics (trading frequency and momentum). Portfolio characteristics are factors that cannot be easily controlled by fund managers. For example, the portfolio size acts as an endowment for the fund manager because a fund manager at our research site cannot unilaterally decide the portfolio size under his/her management. From a managerial perspective, performance evaluation should focus on those factors that managers can control. In our regression analysis, portfolio characteristics constrain the fund managers while trading characteristics provide information about fund managers' ability in trading. Thus, we want to know whether fund managers' trading efficiency is explained more by their endowment or by their ability. We use Vuong's test to compare the explanatory power of portfolio characteristics and trading characteristics in trading efficiency. The results of Vuong's test are shown in Table 5. A significant positive (negative) Z-statistic indicates that the second (first) model is rejected in favor of the first (second) model. In panels A and B of Table 5, Vuong's Z-statistic rejects trading characteristics in favor of portfolio characteristics. Vuong's test suggests that portfolio characteristics (trading diversification and the size of the trading portfolio) have a greater explanatory power than trading strategies. This result provides insights for fund managers' performance evaluation. When evaluating and 
recruiting fund managers, we should recognize the limitations that portfolio characteristics impose on fund managers. In summary, these results suggest that when we evaluate fund managers' performance, we need to condition the evaluation on portfolio characteristics which are the main determinants of trading efficiency.

\section{Conclusion}

This paper provides our research client an alternative method to evaluate fund managers' performance at the transaction level. Instead of using traditional portfolio measures, we innovate from the standard DEA modeling literature by customizing an additive DEA model specifically to evaluate fund managers' performance in their buy and sell transactions. Our relative efficiency measures recognize the pattern of returns over three consecutive time horizons ( 0 to 3 month, 3 to 6 month and 6 to 12 month post-trade periods).

Our efficiency scores provide evidence that fund managers do not have symmetric ability in their buy and sell transactions. This result cannot be discovered from just an aggregate level portfolio performance analysis conducted in prior studies. Some managers do well in buy trades but not in sell trades, while others perform well in sell transactions but not in buy transactions. This asymmetry of relative trading performance as captured by the DEA efficiency scores represents an important advance in the field of performance management in understanding the full dimensions of performance of fund managers.

We also analyze the relationship between fund managers' trading efficiency and portfolio and trading characteristics. While overall there is no significant correlation between fund managers' buy and sell abilities, their buy and sell efficiency are both similarly influenced by common characteristics such as trading diversification and size of trading portfolio. Therefore, we can eliminate 
these common factors as potential explanators of the asymmetry in fund managers' buy and sell performance. The asymmetry between buy and sell performance must be associated with other individual characteristics not measured at our research client.

These results bring our attention to promising directions for future studies of fund managers' performance evaluation. When evaluating and recruiting fund managers, we need to focus on those factors that can reflect fund managers' ability and we should also recognize the limitations fund managers have at the same time. These findings suggest a fruitful path in analyzing detailed trade-level data to determine what drives fund manager efficiency. 


\section{References}

Banker R D, Chang H, Janakiraman S N and Konstans C (2004). A balanced scorecard analysis of performance metrics. European Journal of Operational Research 154(2): 423436.

Banker R D, Chang H and Natarajan R (2007). Estimating DEA technical and allocative inefficiency using aggregate cost or revenue data. Journal of Productivity Analysis 27: $115-272$.

Banker R D and Natarajan R (2008). Evaluating contextual variables affecting productivity using data envelopment analysis. Operations Research 56 (1): 48-58.

Basso A and Funari S (2001). A data envelopment analysis approach to measure the mutual fund performance. European Journal of Operational Research 135(3): 477-492.

Basso A and Funari S (2003). Measuring the performance of ethical funds: A DEA approach. Journal of the Operational Research Society 54 (5): 521-531

Carhart M M (1997). On persistence in mutual fund performance. Journal of Finance 52: 5782.

Chen H L, Jegadeesh N and Wermers R (2000). The value of active mutual fund management: An examination of the stockholdings and trades of fund managers. Journal of Financial and Quantitative Analysis 35: 343-368.

Chen J, Hong H, Huang M and Kubik J D (2004). Does fund size erode mutual fund performance? The role of liquidity and organization. American Economic Review 94: $1276-1302$.

Cheng G, Zervopoulos P and Qian Z (2013). A variant of radial measure capable of dealing with negative inputs and outputs in data envelopment analysis. European Journal of Operational Research 225: 100-105.

Choi Y K and Murthi B P S (2001). Relative performance evaluation of mutual funds: A non-parametric approach. Journal of Business Finance \& Accounting 28(7/8): 853-876. 
Dahlquist M, Engstrom S and Soderlind P (2000). Performance and characteristics of Swedish mutual funds. Journal of Financial and Quantitative Analysis 35(3): 409-423.

Davis J L (2001). Mutual fund performance and manager style. Financial Analysts Journal 57(1): 39-54.

Daniel K, Grinblatt M, Titman S and Wermers R (1997). Measuring mutual fund performance with characteristic-based benchmarks. Journal of Finance 52: 1035-1058.

De Bondt W F M and Thaler R (1985). Does the stock market overreact? Journal of Finance 40: 793-805.

De Bondt W F M and Thaler R (1987). Further evidence of investor overreaction and stock market seasonality. Journal of Finance 42: 557-581.

Eling M (2006). Performance measurement of hedge funds using data envelopment analysis. Financial Markets and Portfolio Management 20: 442-471.

Elton E J, Gruber M J and Blake C R (2012)._Does mutual fund size matter? The relationship between size and performance. The Review of Asset Pricing Studies 2 (1): 31-55.

Ferreira M A, Keswani A, Miguel A F and Ramos S B (2013). The determinants of mutual fund performance: A cross-country study. Review of Finance 17 (2): 483-525.

Green W H (2011), Econometric analysis. Prentice Hall Publisher.

Gregoriou G N (2003). Performance appraisal of funds of hedge funds using data envelopment analysis. Journal of Wealth Management 5(4): 88-95.

Gregoriou G N, Sedzro K and Zhu J (2005). Hedge fund performance appraisal using data envelopment analysis. European Journal of Operational Research 164(2): 555-571.

Haslem J A, Baker H K and Smith D (2008). Performance and characteristics of actively managed retail equity mutual funds with diverse expense ratios. Financial Services Review 17: 49-68.

Hu J L, Yu H E and Wang Y T (2012). Manager attributes and fund performance: Evidence from Taiwan. Journal of Applied Finance and Banking 12 (4): 85-101. 
Jensen M C (1968). The performance of mutual funds in the period 1945-1968. Journal of Finance 23: 389-416.

Jegadeesh N and Titman S (1993). Returns to buying winners and selling losers: Implications for stock market efficiency. Journal of Finance 48: 65-91.

Kerstens K and Woestyne I V (2014). A note on a variant of radial measure capable of dealing with negative inputs and outputs in DEA. European Journal of Operational Research 234: $341-342$

Kumar UD, Roy A B, Saranga H and Singal K (2010). Analysis of hedge fund strategies using slack-based DEA models. Journal of the Operational Research Society 61 (12): 1746-1760.

Lamb, J D and Tee K H (2012). Resampling DEA estimates of inyestment fund performance. European Journal of Operational Research 223: 834-841.

Lozano S and Gutiérrez E (2008). TSD-consistent performance assessment of mutual funds. Journal of the Operational Research Society 59 (10): 1352-1362.

Murthi B P S, Choi Y K and Desai P (1997). Efficiency of mutual funds and portfolio measurement: a non-parametric approach. European Journal of Operational Research 98: 408-418.

Morey M R and Morey R C (1999). Mutual fund performance appraisals: a multi-horizon perspective with endogenous benchmarking. Omega, International Journal of Management Science 27: 241-258.

Pollet J M and Mungo I W (2008). How does size affect mutual fund behavior? Journal of Finance 63: 2941 - 2969.

Prather L, Bertin W J and Henker T (2004). Mutual fund characteristics, managerial attributes and fund performance. Review of Financial Economics 13: 305-326.

Sharpe W F (1966). Mutual fund performance. Journal of Business 39: 119-38. 
Treynor J (1965). How to rate management investment funds. Harvard Business Review 43 : 63-75.

Treynor J and Mazuy K (1966). Can mutual funds outguess the market? Harvard Business Review 44: 131-136.

Wermers R (2000). Mutual fund performance: An empirical decomposition into stockpicking talent, style, transactions costs, and expenses. Journal of Finance 55: 1655-1695. 
Figure 1 Six Time Periods for Annualized Returns

For each transaction, we have returns for six different periods: 12 to 6 months (Pre12-6), 6 to 3 months (Pre 6-3) and 3 months (Pre3-0) prior to the trade date and 3 months (Post0-3), 3 to 6 months (Post3-6) and 6 to 12 months (Post6-12) subsequent to the trade date.

\begin{tabular}{|l|l|l|l|l|l|}
\hline Pre12-6 & Pre 6-3 & Pre3-0 & Post 0-3 & Post 3-6 & Post6-12 \\
\hline & & & & &
\end{tabular}

12 months 6 months 3 months Trading 3 months 6 months 12 months

Prior Prior Prior Date After After After


Figure 2 Correlation of Buy and Sell Efficiency Ranks

Figure 2 shows fund managers' rank for sell efficiency plotted against their buy efficiency.

The X-axis shows fund manager's buy rank while Y-axis is fund manager's sell rank. The 18 dots represent the 18 fund managers' performance in buy trades and sell trades. The rank correlation between fund managers' buy and sell efficiency ranks is insignificant (correlation $=-0.1703(\mathrm{p}$-value $=0.50))$.

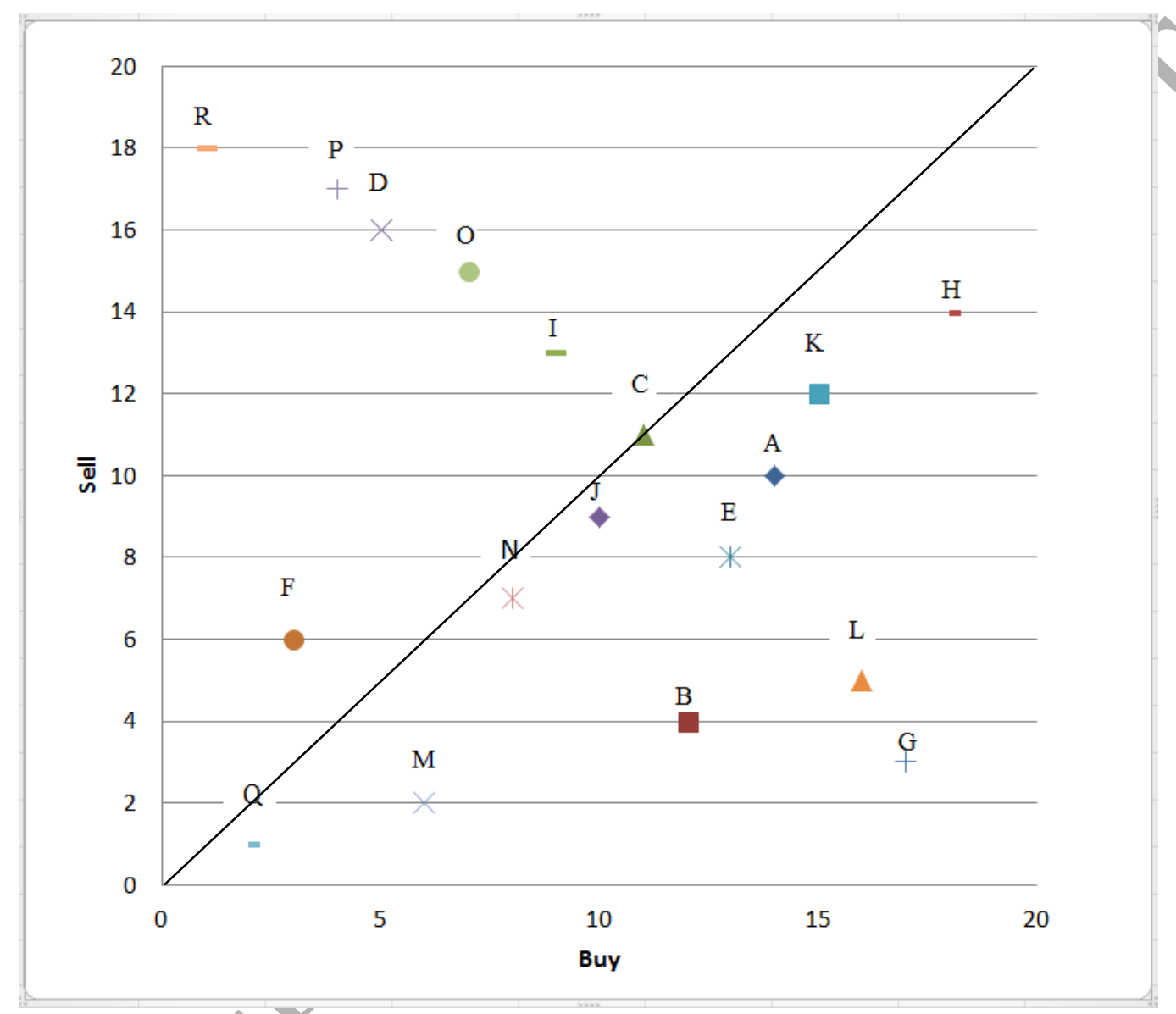




\section{Table 1 Sample Characteristics}

Table 1 reports descriptive statistics of the 23,408 transactions (11496 are from the buy sample and 11912 are from the sell sample), including the mean, median, and standard deviation of the cumulative return prior to and subsequent to the trade date for each transaction. Pre12-0, Pre6-0, Pre3-0 represent 12 months, 6 months and 3 months prior to the trading date and Post0-12, Post0-6, Post0-3 represent 12 months, 6 months and 3 months subsequent to the trading date.

\begin{tabular}{lcccccc}
\hline & \multicolumn{5}{c}{ Sample Characteristics (Cumulative Adjusted Returns) } \\
\hline & \multicolumn{3}{c}{ Buy Transactions } & \multicolumn{3}{c}{ Sell Transactions } \\
\cline { 2 - 7 } Period & mean & median & Std Dev & mean & median & Std Dev \\
\cline { 2 - 7 } Pre12-0 & 6.50 & 2.79 & 29.85 & 5.13 & 1.14 & 29.85 \\
Pre6-0 & 2.43 & 1.06 & 19.53 & 0.57 & -1.08 & 19.11 \\
Pre3-0 & 0.68 & 0.23 & 13.13 & -0.55 & -1.13 & 13.09 \\
Post0-3 & -0.04 & -0.57 & 13.55 & 0.30 & -0.47 & 12.29 \\
Post0-6 & 0.40 & -1.03 & 19.36 & 0.29 & -1.62 & 17.92 \\
Post0-12 & 0.84 & -2.26 & 28.57 & 1.00 & -1.12 & 25.82 \\
\hline
\end{tabular}


Table 2 Distribution of Estimated Efficiency Scores

\begin{tabular}{|c|r|c|r|}
\hline \multicolumn{2}{|c|}{ Distribution of Buy Efficiency Scores } & \multicolumn{2}{|c|}{ Distribution of Sell Efficiency Scores } \\
\hline Quantile & Estimate & Quantile & Estimate \\
\hline $100 \%$ & 1.0000 & $100 \%$ & 0.9993 \\
\hline $99 \%$ & 0.9993 & $99 \%$ & 0.9983 \\
\hline $95 \%$ & 0.9982 & $95 \%$ & 0.9972 \\
\hline $90 \%$ & 0.9962 & $90 \%$ & 0.9925 \\
\hline $75 \%$ & 0.9879 & $75 \%$ & 0.9722 \\
\hline $50 \%$ & 0.9437 & $50 \%$ & 0.8636 \\
\hline $25 \%$ & 0.7973 & $25 \%$ & 0.6463 \\
\hline $10 \%$ & 0.5540 & $10 \%$ & 0.4471 \\
\hline $5 \%$ & 0.3305 & $5 \%$ & 0.0854 \\
\hline $1 \%$ & 0.0565 & $1 \%$ & 0.0000 \\
\hline $0 \%$ & 0.0000 & $0 \%$ & 0.8848 \\
\hline Mean & 0.8478 & mean & 0.1894 \\
\hline Standard deviation & 0.2145 & Standard deviation & \\
\hline
\end{tabular}


Table 3 Fund Managers' Rank for Buy and Sell Efficiency

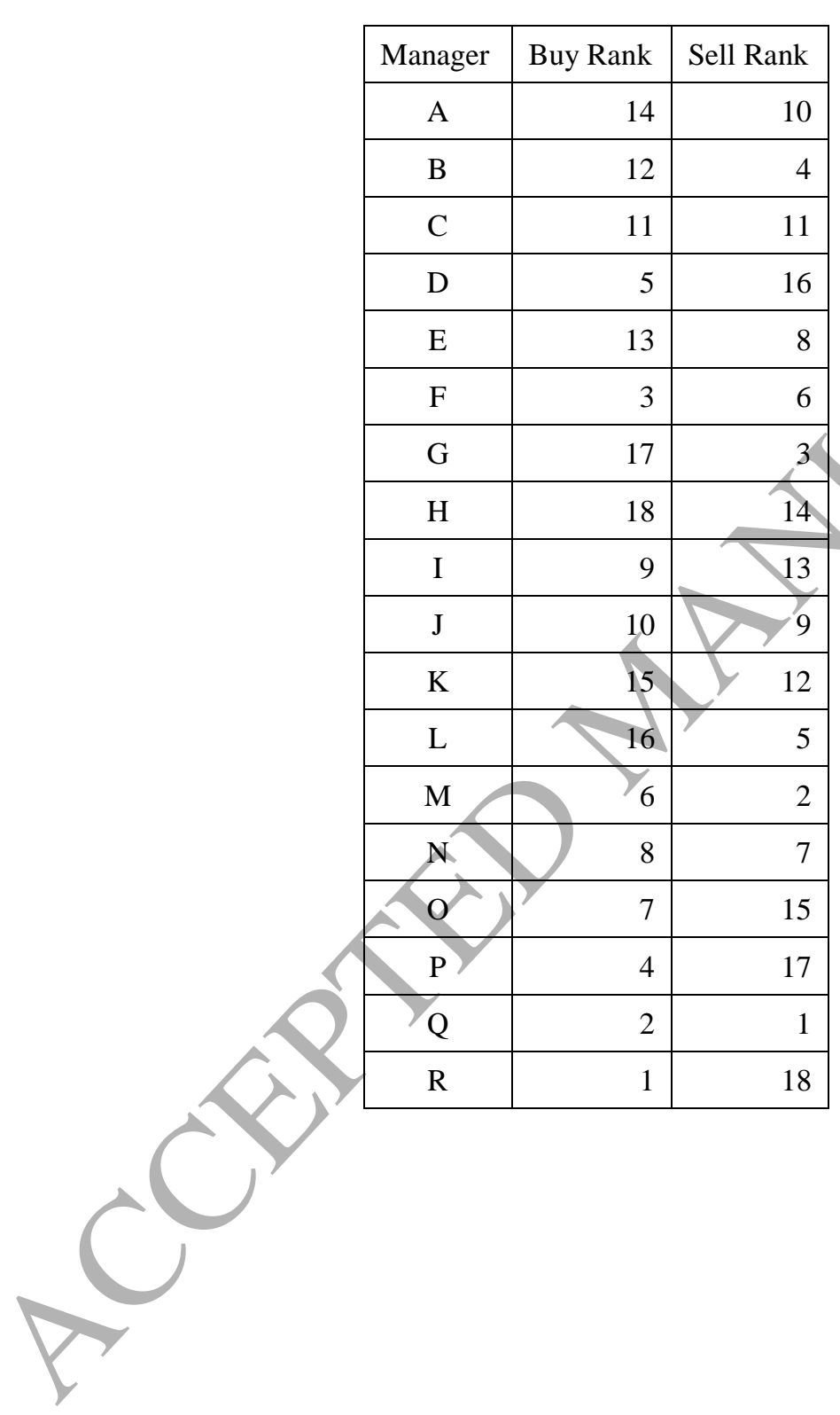


Table 4 Regression Estimation of the Impact of Portfolio and Trading Characteristics on Fund Managers' Buy and Sell Trading Efficiency Scores

Table 4 presents results from the regression model for the analysis of portfolio and trade characteristics. HHI measures trading diversification and is defined as the sum of squares of the market value of stocks traded by the fund manager divided by the market value of his/her trading portfolio. Size is the relative size of each fund manager's trading portfolio (measured as the market value of fund manager i's portfolio divided by the total market value of all fund managers' portfolios). TFreq is trading frequency measured as the number of times a stock is bought or sold by the fund manager. Ret. $3 \mathrm{M}$ is the past 3 month return of the traded stock.

\begin{tabular}{|c|c|c|c|}
\hline & Buy Sample & Sell Sample & Diff_(Buy-Sell) \\
\hline Variable & Coefficient & Coefficient & p-value \\
\hline Intercept $\left(\alpha_{0}\right)$ & $0.7633 * * *$ & $0.7933 * * *$ & 0.3648 \\
\hline HHI $\quad\left(\beta_{1}\right)$ & $-3.6166^{* * * *}$ & $-3.3926^{* * *}$ & 0.8401 \\
\hline Size $\quad\left(\beta_{2}\right)$ & $0.5587 * * *$ & $0.5038 * * *$ & 0.5349 \\
\hline TFreq $\quad\left(\gamma_{1}\right)$ & $0.0057 * * *$ & $0.0050 * * *$ & 0.1240 \\
\hline \multirow[t]{2}{*}{ Ret. 3M $\quad\left(\gamma_{2}\right)$} & $-0.0427 * * *$ & $-0.0498 * * *$ & 0.9182 \\
\hline & $\mathrm{R}-\mathrm{sqr}=0.36$ & $\mathrm{R}$-sqr $=0.41$ & \\
\hline
\end{tabular}


Table 5 Relative Information Content

Table 5 reports Vuong's test results of relative information content in portfolio characteristics and trading characteristics. A significant positive (negative) Z-statistic indicates that the second (first) model is rejected in favor of the first (second) model. Panel A (B) reports Vuong test results in the buy (sell) sample.

\begin{tabular}{|l|c|c|}
\hline \multicolumn{3}{|c|}{ Panel A---Buy sample } \\
\hline BUY_Competing models & Vuong's Z - statistic & p-value \\
\hline HHI + Size vs. TFreq + Momentum & 26.85 & 0.000 \\
\hline HHI vs. TFreq + Momentum & 14.30 & 0.000 \\
\hline Size vs. TFreq + Momentum & 27.60 & 0.000 \\
\hline Size vs. HHI + TFreq + Momentum & -4.62 & 0.000 \\
\hline HHI vs. Size + TFreq + Momentum & 0.28 & 0.770 \\
\hline HHI vs. Size & 4.14 & 0.000 \\
\hline
\end{tabular}

\begin{tabular}{|l|c|c|}
\hline \multicolumn{2}{|c|}{ Panel B---Sell sample } \\
\hline SELL_Competing models & Vuong's Z - statistic & p-value \\
\hline HHI + Size vs. TFreq + Momentum & 19.58 & 0.000 \\
\hline HHI vs. TFreq + Momentum & 8.66 & 0.000 \\
\hline Size vs. TFreq + Momentum & 37.80 & 0.000 \\
\hline Size vs. HHI + TFreq + Momentum & -1.80 & 0.070 \\
\hline HHI vs. Size + TFreq + Momentum & 0.60 & 0.550 \\
\hline HHI vs. Size & 1.68 & 0.090 \\
\hline
\end{tabular}

